Polina Ivanova*

\title{
Civil Society Groups Involved with International Students in Japan: Typology and Social Capital Generation
}

\author{
https://doi.org/10.1515/npf-2019-0058
}

Received October 21, 2019; accepted May 24, 2020

\begin{abstract}
This article explores the interaction between civil society organizations in Japan and incoming international students to illustrate how the nonprofit sector can be conducive to social capital generation in diverse groups in the short-term. Based on interviews, participant observation and document analysis, this study examines motivations of nonprofit staff and volunteers to get involved with international students and connects them to students' expectations and needs. The paper suggests ways of improving engagement between Japanese civil society organizations and international students to benefit all the stakeholders.
\end{abstract}

Keywords: civil society organizations, internationalization of higher education, social capital, international students in Japan

\section{Introduction}

The internationalization of higher education in Japan is an ongoing process that has been invigorated by globalization since the 1990s. From the beginning, it has been a top down reform initiated by the Japanese government and implemented by the Ministry of Education, Culture, Sports, Science and Technology (MEXT). Although the internationalization of higher education comprises many aspects, this study focuses only on incoming overseas students. Some of the relevant MEXT initiatives include 300,000 International Student Plan and Top Global University Project. The Top Global was launched in 2014 and is scheduled to run until 2023. It

*Corresponding author: Polina Ivanova, Department of International Relations, Ritsumeikan University, Kyoto, 603-8577, Japan, E-mail: gr0162rv@ed.ritsumei.ac.jp. https://orcid.org/00000001-6170-0690 
has an aim of enhancing international competitiveness of Japanese universities and budget of $¥ 7.7$ billion (\$US 77 million) for 37 projects. The Top Global University Project was preceded by the Global 30 (2009-2013), and both projects are expected to support the 2008 plan of the Japanese government to recruit 300,000 international students by 2020. The Ministry of Economy, Trade and Industry (METI) also prioritize attracting more "highly-skilled foreign professionals" (METI 2018, 2019) "including overseas students studying in Japan” (METI 2019) to Japanese companies.

The main objective of this research is to explore how civil society groups help international students build social capital. The study is guided by the following questions: what motivates civil society organizations (CSOs) in Japan to get involved with the international students, and how their involvement meets students' expectations and needs? To help answer the main research questions, the following background questions are also explored: what types of CSOs engage with international students; how closely they are related to the government and/or private sector; what types of issues they are willing to address; what strong points and areas of improvement their approach and activities have.

The significance of the study lies in re-contextualizing social capital theory using the case of Japanese CSOs interacting with inbound international students. It also explores the question of social capital generation in the short-term, along with factors contributing to social capital creation through interaction between actors from diverse groups. The author follows Pekkanen's (2006) definition of civil society as "the organized, nonstate, nonmarket sector" (3) which includes all types of voluntary groups and associations, collectively referred to as CSOs. While the concept of civil society has Western European roots and dates to the late 19c., Japan has long-standing traditions of civil society groups of its own. Japanese CSOs have several specificities compared to their Western counterparts: they are numerous but small; they closely cooperate with the government, and they are active in the service provision and passive in political advocacy (Pekkanen 2006; Schwarz and Pharr 2003; Tsujinaka 2010; Vogt and Lersch 2007). Among historical factors that shaped Japanese CSOs, the researchers count the fact that they were excluded from the "iron triangle" - the partnership between the ruling party, bureaucracy and big businesses defining the socioeconomic life of the country after the World War II. Secondly, the NPO Law allowing the citizens to register their nonprofit was passed only in 1998, relatively late compared to other advanced nations.

The internationalization of higher education is defined by Knight (2004) as "the process of integrating an international, intercultural or global dimension into the purpose, functions or delivery of post-secondary education” (Knight 2004, 11). This study focuses on international students enrolled in graduate level programs 
(master's and doctoral) taught in English at Japanese universities. Even though this group is a minority among the student population in Japan, the numbers of graduate international students in Japanese universities have been increasing over the recent years: 50,184 graduate international students out of the total number of 289,980 international students in 2018 versus 32,666 graduate international students in 2008 and 20,483 in 1998 (JASSO 2015, 2019). Moreover, this group is one of main targets for the Japanese government to boost the country's global competitiveness and to revitalize the economy. Another reason to focus on international students enrolled in English-taught programs is that they come from a variety of cultural and linguistic backgrounds, significantly different from Japanese. Therefore, they are likely to experience specific challenges in cultural adjustment compared to their peers studying in Japanese-taught programs who mainly come from East Asian nations having more in common with Japan linguistically and culturally. Difficulties in sociocultural adaptation may be further reinforced by geographical isolation of Japan as an island country.

\section{Methodology}

This is a qualitative study relying on such methods of data collection as participant observation, semi-structured interviews, and textual analysis of key documents of relevant organizations. The author visited, participated in daily activities, and studied documents of 25 CSOs, mainly volunteer groups and small non-profits across four prefectures in the Kansai area of Japan: Hyogo, Osaka, Kyoto, and Shiga, and interviewed their representatives. A maximum variation sampling method was used to ensure that various types of organizations are included in the study (Johnson and Christensen 2014). Interviewing was conducted with selected CSO representatives: staff and volunteers (23 interviews), international graduate students studying in English (15 interviews), and university staff in charge of facilitating CSO engagement with international students (3 interviews). All the interviews were transcribed and coded. Participant observation was another important source of data to complement interviewing and enhance validity of the study. Some interviews with CSO staff and volunteers did not reveal much because the informants tended to provide socially expected answers to the interviewer's questions or were overly concerned about using appropriate vocabulary in the interviews: "I think I had to use more key words related to international activities such as diversity, multicultural, co-existing and so on” (Staff, CSO Type 2.1., February 8, 2018). Observation of the most CSOs started in December 2016 and continued until December 2018, and interviewing took place between October 2017 and December 2018. 


\section{Conceptual Framework}

Social capital theory based primarily on Robert Putnam's tradition serves as the main conceptual framework for this study. Putnam defines social capital as "connections among individuals - social networks and the norms of reciprocity and trustworthiness that arise among them" (Putnam 2000, 19). "Social capital generation", "formation" and "creation" are used as synonyms throughout the study. Besides, motivation theories are used to explain motivations of the CSOs to get involved with international students. The study builds on extensive scholarship on civil society in Japan and internationalization of higher education and intends to bring these two concepts together by using social capital theory.

Putnam's work provides distinction between bonding social capital occurring within homogenous groups and bridging social capital formed within socially heterogeneous groups. Putnam notes different functions of those types: "bonding social capital is ... good for getting by" while bridging social capital is crucial for "getting ahead" (Putnam 2000, 23). Bridging social capital requires one to connect with people unlike oneself in terms of social, political, religious, and professional identities. This type becomes particularly relevant for exploring interactions between international students and local CSOs. Putnam's suggestions for increasing bridging social capital include team sports, arts, and cultural activities, and these are exactly the types of activities that CSOs usually organize and that international students enjoy.

Viewpoints on social capital generation differ among scholars. Earlier studies (Fukuyama 2001; Putnam 1993) focused more on long-term factors, such as religion, tradition, shared historical experience, governments and education system on the macro-level, or within and between households on the micro- and mesolevels (Coleman 1988). Later empirical studies explored social capital generation in the short-term in a variety of contexts, such as business environment through a mix of local cooperation and competition (Soubeyran and Weber 2002) or among college students through their use of social media (Ellison, Steinfield, and Lampe 2007). However, specific mechanisms or factors contributing to social capital generation remain under-researched.

\section{Literature Review}

Previous researches on social capital among international students have shown the following tendencies. Neri and Ville (2008) find a positive impact of social capital generation on international students' well-being but not their academic performance. However, studies by Vaughan et al. (2014) demonstrated a positive 
correlation between social capital and academic achievement. Researchers have also found a tendency towards homophily (forming friendships with similar ones by ethnicity, age and role), which could be interpreted as a sign of prevalence of bonding social capital among international students (Neri and Ville 2008; Vaughan et al. 2014).

The lack of social capital negatively affects international students. According to Vaughan et al. (2014), majority students outperform minority students, having better access to formal peer-learning schemes, tutoring, having seniors in their network as role models for their career. Most scholars agree that increased contact with host nationals improves life satisfaction, creates social connectedness, decreases loneliness, homesickness and chances of dropout among international students (Hendrickson, Rosen, and Aune 2011; Neri and Ville 2008; Vaughan et al. 2014).

Few studies have examined the role of volunteer organizations on and off campus in international students' sociocultural adaptation. Research has been mostly limited to several publications viewing involvement with volunteer organizations within a broader framework of international student community engagement alongside with other activities (Fleischman, Raciti, and Lawley 2010; Marginson et al. 2010; Owens and Looms 2010) or considering international students among other student categories (Krause 2005). Other studies were limited to specific organizational types: for instance, Encinas (2016) focused on Erasmus Student Associations in assisting international students' integration in Spain while Harvey (1991) examined the role and functioning of three ethnic student associations (African, Chinese and Egyptian student organizations) in one American university. However, there has not yet been a comprehensive study involving various types of international student support organizations and exploring factors of social capital generation within them.

\section{Research Findings}

\subsection{Typology of the Volunteer Groups Involved with International Students in Japan}

Field research helped identify the following types of organizations engaged with international students in the Kansai area:

\subsubsection{On-Campus Associations}

(a) Support groups for international students. These groups are usually directly organized and continuously supervised by universities accepting international 
students. All members are university students, usually belonging to the majority group on campus (Japanese undergraduate students). Typical events include cooking parties, sightseeing tours, and seasonal events, such as making rice cakes in the New Year period or cherry blossom viewing in spring. Some universityaffiliated groups may have equal numbers of Japanese and foreign student members, and yet others may be composed of predominantly international students. Usually, the latter groups aim to show existing cultural diversity on campus. Five organizations in this study belong to this type.

(b) Formally registered clubs and circles at the university level. Initially created and maintained by domestic students, they have recently started accepting international student members. This process does not always go smoothly: international students often find it difficult to commit to the strict discipline including mandatory meetings 3-4 times a week, while domestic students often have a sceptic attitude towards international members and are not very receptive. Even if international students get accepted formally as a club member, they often experience rejection on the personal level and eventually stop coming to the club or circle due to this reason. This type is represented by three groups in this study. (c) Alumni networks connecting both domestic and international graduates. Some universities make conscious efforts to bring together their current students and graduates, both domestic and international. Such networks or associations are funded by membership fees and are more loosely structured compared to the previous types. Their activities include networking events, workshops with guest speakers and creating newsletters. Only one organization of this type is found in this sample.

(d) Ethnic-based associations at the university level. They usually include students from a certain country and may also attract a limited number of members interested in this country, learning its language, or planning to study abroad. Their status is ambiguous: not being formally registered, they still have hierarchy but no formal election process. Although still supervised by the universities they are affiliated to, their members have more autonomy in choosing their events and managing the organization. This type is represented by two organizations in the study.

\subsubsection{Off-Campus Groups}

(a) Groups initiated and funded by local governments. Organizations of this type have several professional staff members and many volunteers, mainly older men (retired company employees) and housewives in their 50-70s with a limited English proficiency. Typical activities include organized sightseeing tours and workshops featuring traditional local crafts. They may also offer free Japanese 
classes for beginners, usually taught by volunteers without specialized training or teaching experience. Most CSOs of this type were founded in the 1980s as a part of Prime Minister Nakasone internationalization policies (Borg 2018; Otmazgin 2018), were initially related to sister city movement and later repurposed for domestic international exchanges known as local level internationalization or "inward internationalization" (uchinaru kokusaika) (Aiden 2018). Six organizations in this study belong to this type.

(b) Groups initiated and funded by the central government. This type is represented by one CSO in the study funded by the MEXT and employing professional staff and semi-professional volunteers: language classes are taught by students of Japanese language departments preparing to become language instructors for foreigners. They have good or limited English proficiency and belong to the younger generation in their 20s, 30s or 40s. Their main function is to assist international students in finding employment in Japan, and their activities include language classes, preparing students for job interviews, company visits, job fairs and a limited number of cultural experiences.

(c) Ethnic friendship associations at the municipal level include students from a specific country and host nationals interested in this country, its language and culture, and promoting international exchange on bilateral level. The organizations are supervised by the city governments they are affiliated to but receive no permanent funding and raise funds by providing language and culture classes and charity bazaars. Two CSOs in this sample belong to this type.

(d) Officially registered nonprofits (NPOs). Similar to the previous type, their activities do not focus primarily on international students. Rather, they have another mission (e. g. providing shelter to homeless animals) and recruit international students as volunteers among other population categories. This empowers international students to be active agents in the host society and serve the broader community instead of simply receiving services from volunteers like in most above-mentioned organizations. The absence of initial emphasis on "foreignness" of international students also makes their approach radically different from all the other CSO types. However, there is still a segregation between foreign and Japanese volunteers in their organizational practices (e. g. sitting at separate tables for lunch). Two CSOs in this study belong to this type.

(e) Grassroots organizations initiated by and centered around a leader. One group in this study composed of retired Japanese volunteers belongs to this type. It is not organized by the government and is supported by membership and participation fees. The main type of activity is sightseeing tours, and international students may not be the main target. They are open to any foreigners in Japan and treat them as guests or temporary visitors, regardless of their actual immigration status. As the main purpose of the organization is to train their Japanese members to become city 
Table 1: International student support associations in the Kansai area of Japan.

International student support associations

\begin{tabular}{ll}
\hline On-campus groups & Off-campus groups \\
1.1. University groups for & 2.1. Groups affiliated to local \\
international students & governments \\
1.2. University circles/clubs & 2.2. Groups affiliated to the central \\
& government \\
1.3. Alumni networks for both domestic and & 2.3. Ethnic friendship associations \\
international graduates & at the city level \\
1.4. Ethnic associations at the university level & 2.4. NPOs \\
& 2.5. Grassroots \\
& 2.6. Informal hobby groups \\
\hline
\end{tabular}

guides, their activities are more focused on Japanese members than foreign participants, and the latter are merely used as training models for volunteers.

(f) Informal hobby groups. Those groups are not formally registered and typically recruit new members using online media such as Instagram or meetup.com. Their activities are centered around a shared interest, such as arts or sports, and they attract international students by their more relaxed attitude and practices compared to official university clubs and circles. This type is represented by two CSOs in this study.

The types of the organizations are summarized in Table 1 situating organizations from more top-down in the upper part of the table to less formal and more bottom-up in its lower part. Employing Haddad's terminology (2007), the topdown types could be called "embedded organizations" as those having "close, ongoing relationships with the government" (164), directly or through universities that are under the MEXT supervision. This partially confirms a dominant view in civil society studies that Japanese CSOs are wide-spread and active but because of its top-down character and close affiliation to the government are sometimes viewed as implementing agencies (Reimann 2010; Schwarz and Pharr 2003). However, the existence of several other organizational types also challenges this opinion.

\section{Interviews with CSOs}

The interview questions for the CSO representatives were based on three main pillars: 1) their motivations to start activities with international students - both individual and organizational motivations, 2) expectations they had before the 
activity and whether they were met by their actual experience, and 3) challenges that they faced in the process. The findings are presented below according to the main themes of the interviews.

\subsection{Motivations}

Regarding the CSO motivations to get involved with international students, individual motivations often differ from organizational ones. Organizational motivations were often quite general and similar to missions statement on the CSO website: "cross-cultural understanding" was mentioned by seven interviewees and "multiculturalism" by three, or occasionally more specific such as "help international students find a job in this city" and "promote our city as a student city" (Staff, CSO Type 2.2., October 19, 2017). Individual members' motivations included: practicing language skills (mentioned by eight interviewees), making friends with other members (16 interviewees) or helping foreign members in the community (two participants). Organizational and individual motivations get closest to each other in case of grassroots organizations or NPOs where they often sound identical: "teach our club members how to be good guides" (Volunteer, CSO Type 2.3., December 22, 2017) or "form a network of people who love animals" (Staff, CSO Type 3.4., March 11, 2018).

Analyzing motivations, this study follows a distinction of extrinsic, or externally oriented, and intrinsic, or internally oriented motivations from social psychology (Deci 1971). The most common was a combination of extrinsic and intrinsic motivations, such as interest in foreign languages/cultures (intrinsic motivation) and desire to help foreign community members (extrinsic). Some interviewees had exclusively intrinsic motivation: developing professional skills to showcase in their CV and obtaining intercultural communication experience useful for the future career. Acknowledging a purely extrinsic motivation was rare, and this included seeing foreigners in Japan as a potential social problem: "we don't know how to cope with foreign people” (Staff, CSO Type 2.1., February 4, 2018). The staff in charge of event planning and hiring viewed the CSO involvement with foreigners as a preventive action: "We have to be more careful about the first action toward those people. If they have a bad impression or bad experiences, they might have hatred and disappointment toward Japanese people and Japan ... If migrant children are bullied at schools or have bad experiences, they might become bad persons, hooligans, hoodlums, and that's gonna be a start of a vicious circle" (Staff, CSO Type 2.1., February 4, 2018).

The "Need Theory" (McClelland 1987) was also used to analyze individual motivations of the CSO representatives. Generally, CSO professional staff or 
leaders/managers were motivated by "achievement" or "power”, while "affiliation" was a common motivation type among volunteers. However, the word "power" was never directly used in the interviews; it took the form of "leadership" or "impact" in case of CSO staff. Similarly, they preferred to talk about "results" instead of "achievement”, while "affiliation" was referred to as "doing things with others", "making friends" or "belonging”.

\subsection{Expectations and Reality}

Regarding the interviewees' expectations, most participants (18 out of 23 respondents) reported their expectations being met by their actual experience of working or volunteering for the CSOs. Some aspects that interviewees evaluated as positive included:

1. Feeling of strong connection among the members: "the main reward we get is the friends we make. This group is more than event-planning; it's something similar to organizing a party with your closest friends because we all actually stick together" (Volunteer, CSO Type 1.1., March 1, 2018).

2. Satisfaction of personal contribution to a good cause: "I now feel proud of myself a bit in doing volunteer things. It would be very sad if international students only stay to study and go back without any experience interacting with Japanese people and society” (Volunteer, CSO Type 2.4., January 29, 2018).

3. Flexibility of their organization: "The best part of the group is that it is easy to be absent whenever you want and then return to the group whenever you want, so it is very comfortable. There is no such kind of obligation or anything” (Volunteer, CSO Type 2.1., November 29, 2018).

4. Feeling of belonging: "I finally feel I belong ... I found my community; we can discuss all sorts of things together” (Volunteer, CSO Type 2.6., July 23, 2018).

The remaining five interviewees reported that the actual experience was below their expectations: "I wish I had more connections, I made a few, but my expectations were higher" (Volunteer, CSO Type 1.3., March 11, 2018). This participant in charge of the newsletter and event planning perceived participation levels and interest in cross-cultural events as low for both domestic and foreign students and was feeling disappointed as a result. A coordinator assisting international students with their job hunting stated: "The more I do, the more I realize how deep this area is and the more problems I see” (Staff, CSO Type 2.2., October 19, 2017). This staff reported overwhelms and quit her job several months later. 


\subsection{Challenges}

Areas of dissatisfaction included frustration with other stakeholders' behavior, such as expressed by a volunteer Japanese language teacher in regard to her foreign students: "I want them to come to class every time, and they don't, for some cultural or religious reasons”, (Volunteer, CSO Type 2.1., February 11, 2018). Others complained about difficulties recruiting new members (Volunteer, CSO Type 1.1., March 1, 2018) or inactivity of the existing members: "the attitude of global students: because they are in Japan just for 2 years, they are somehow not so motivated to have a deeper connection or cultural experience" (Volunteer, CSO Type 1.3., March 11, 2018). Most organizations started by recruiting volunteers through personal networks: typically, they invited friends or former students. However, after reaching certain stages of organizational development, more formal ways of recruitment are needed.

Several interview participants did not acknowledge having any challenges at all during their activities, and only one out of 23 respondents on the CSO side admitted experiencing a language barrier as a challenge. However, participant observation helped reveal some other challenges that did not come up in the interviews. Most observed challenges are interrelated and represent a combination of intercultural, linguistic, and managerial factors.

First, a lack of intercultural communication skills from both CSOs and international students' side often led to misunderstandings ranging from unnecessary frustrations to conflictual situations. Interacting with others unlike ourselves often leads to identity re-negotiation (Ting-Toomey 2015). Volunteers' behavior sometimes reveals their apprehension that their identity is being put into question and resulting embarrassment. For example, Japanese volunteers coming from Osaka prefecture for a one-day guided tour in Kyoto did not know all the details about bus stop systems while international students who lived in Kyoto and knew those details better, corrected them. The volunteers looked very embarrassed and repeated several times: "foreigners know better than us" (Fieldnotes, December 22, 2017). Similarly, four interviewees reported feeling ashamed about not knowing everything on Japanese traditional culture.

Another barrier to intercultural understanding was a tendency to stereotyping in the form of tactless comments or questions that international students found frustrating or hurtful. "I quit because one of the old women there insulted me, that's how I take it. The way of counting in Japanese is very complex and differs whether you count people, objects etc. It was difficult for me, and she said: "Japanese kids 6 years old can do it, why can't you do?" Comparing me to a sixyear-old boy, that was an insult”, (Student, August 16, 2018). 
Language barrier became particularly important in case of email communication where non-verbal cues are absent and where it is often aggravated by the lack of presentation skills of the CSO representatives, and inadequate coordination with universities acting as intermediaries between CSOs and international students. Event announcements via university email or learning management system often include unclear explanations of the nature of activities or focus of the organization, multiple typos or incorrect use of English words, confusion of the contact information by the university staff, incorrect communication of the venue location. As a result, the CSO messages do not always reach their target recipients.

Some CSOs also lacked clear vision of their involvement with international students which manifested as a lack of consistency in their activities, not getting back to students, or their preference of one-time events to a series of events or longer-term programs that would be more conducive to social capital generation (Aldrich 2012; Maclure and Sotelo 2014; Muriisa and Jamil 2011; Mirwaldt 2012).

\section{Interviews with International Students and University Staff}

International students' motivations to engage with CSOs ranged from experiencing visible parts of Japanese culture (“I am here only for the kimono!", Student participant CSO Type 2.1., December 15, 2018) to more complex and profound search for belonging and building their community ("I found it a bit difficult to build my social network in a society that is so radically different from home", Student participant CSO Type 2.6., July 25, 2018). Accordingly, their expectations also varied from low to high. This means that CSOs working at more superficial levels of providing sightseeing tours and cooking events also have their clientele as well those organizations working on students' integration. However, simply entertaining students or even helping them adjust temporarily may not be enough given the government's goal to retain high-quality human resources in the country.

Among international students in this sample, there was a distinction in their strategies of getting support and their choices of the CSO types which reminds of Putnam's classification of social capital actors, such as "machers" and "schmoozers" (Putnam 2000). Machers are defined as those "who invest lots of time in formal organizations" while schmoozers are those "who spend many hours in informal conversations and communion" (Putnam 2000, 93). Schmoozers' social life is "less organized and purposeful, more spontaneous and flexible" compared to that of machers (Putnam 2000, 94). Some international students preferred to come to their university support center and ask for services at the 
counter while others were inclined to rely on their informal networks such as friends. The first type ("machers") was more oriented towards membership in official organizations on and off campus while the second type ("schmoozers") was likelier to join informal hobby groups. "If it were a formal club at university, I don't think I would go. I don't think I would like it as much” (Student, October 18, 2018).

International students often found it difficult to relate to volunteers due to cultural, linguistic and generational differences. Many students were also discouraged from participation in the activities with official CSOs because they perceived their practices as too cold, formal, and not encouraging a genuine connection (9 out of 15 participants). Several graduate students in this sample searched alternative types of communities through online media. Those informal hobby groups were not officially registered entities; however, they provided emotional support to students more efficiently. Students found attractive more flexible formats and more relaxed practices of those informal groups compared to official organizations.

International students also got involved in formal organizations at different levels: from passive membership (joining the group at the beginning and attending few events throughout the membership period) to active (attending numerous events and participating in event planning) and highly active (assuming leadership positions such as a president, secretary, etc.). However, international students are typically treated as guests, not hosts or organizers both in universityaffiliated and off-campus groups. While universities recognized the value of empowering international students, they struggled to put this into practice (University staff, August 3, 2018).

Coordination between universities, CSOs and individuals is another key issue. Currently, one of the most successful examples of CSO involvement with international students is a host family program run jointly by a major university in Kansai and a network of local CSOs for 20 years and matching over 200 families and international students each semester. As the university staff in charge of the program states: "we are really fortunate to be able to work with these groups. We do work with host families [directly] but these groups have really experienced leaders involved, so they take care of those host families who are new. And also, at the meeting, there are all those experienced leaders as well as not very experienced members. So, if some groups have some questions, concerns and alike, other members respond, so it's really nice and I really appreciate the network that we have" (University staff, December 7, 2018). This program has also a wellestablished system of collecting feedback from all participants at different stages while other CSOs and universities only receive it on an ad hoc basis or do not collect feedback at all which hinders their learning. 
According to Tsujinaka (2010), social capital in Japan is characterized by "networks, trust and reciprocity norm through its traditional structures and relationships” (258). This has a number of implications: since international students are not a part of traditional structures and relationships; a priori trust may be low, and reciprocity norm may not work if international students are only treated as guests and not given opportunities to actively contribute to the local community.

\section{Conclusions}

The field research findings confirm that most Japanese CSOs involved with international students see themselves as service providers and students as aid recipients, in line with the previous literature (Vogt and Lersch 2007). Few organizations view students as active agents empowering them to volunteer at the local community, even though this seems the best working approach for building long-term social networks. One CSO in this sample was approaching students as "models" or "test persons" for trying out on them the members' skills as city guides. Even though their tours are quite informative and interesting, they are not able to attract and keep many participants as their current approach does not seem very encouraging or productive for establishing trustful relationships.

Next, most CSOs in the sample are helping international students adapt short-term to the Japanese society while still very few help them integrate longterm into the society through job-hunting support. This confirms that the members of most CSOs view foreigners as temporary visitors (Stevens 1997) and strive to provide them with experiences of the best aspects of Japanese society, hence a strong emphasis on sightseeing tours. Another controversial aspect is a strong emphasis on "foreignness" of international students by most organizations: on one hand, it often motivates Japanese CSOs to seek contact with international students, but at the same time, this approach prevents them from building deeper connections. The misalignment of volunteers' motivations and organization's goals and values, and mismatch between international students' expectations and those of CSO representatives discussed in the sections above can also inhibit social capital generation.

The findings show that universities have an important part to play in facilitating the interaction between international students and CSOs, and a good coordination between the actors is a key to success. Social capital can be generated through a series of events or longer-term programs promoting trust and shared values between participants. However, cross-cultural miscommunications, language barrier and lack of presentation skills often obstruct social capital generation. Currently, many international students remain 
unaware of CSO activities because of frequent miscommunications. Besides, building ties between domestic and international students is often implicitly considered newcomers' responsibility. The current tendency in Japanese universities is that international students often complain of being unable to overcome an invisible wall between them and Japanese peers (Interviews with students, February 26, 2018; August 16, 2018; December 1, 2018) while international support office only encourages them to try harder to make friends with domestic students (University staff, August 3, 2018).

\section{Recommendations}

Based on the conclusions above, the final section presents suggestions for the main actors: CSOs, international students, and Japanese universities.

First, CSOs should view international students as active agents and community members and work more on helping international students integrate to Japanese society and not just adapt temporarily. Formally registered organizations should learn from best practices of informal groups and think of more flexible formats and modalities of work as flexibility is found important for both Japanese volunteers and international students. While organizing their activities, they also need to provide socially acceptable ways for new visitors to come again or reconnect again with the group if they wish to do so. Many public activities are onetime events, so even if participants enjoy the experience, they are not very likely to meet the group members again or stay in touch with each other after the event. This way, precious opportunity of creating stronger ties is lost, and potential social capital is not generated.

Better coordination between the key actors is crucial to shape programs that would better respond to international students' needs, and accurately deliver CSO message to students. Without proper coordination with universities and consultations with international students themselves, CSO interventions risk to be driven by the organization's own agenda rather than needs of students and/or local community (Maclure and Sotelo 2014) which can hinder social capital formation.

Bridging social capital can be generated on the university level through mentoring and "buddy system" for the newcomers (Neri and Ville 2008), improved access of international students to formal peer-learning schemes and tutoring (Vaughan et al. 2014). Making friends between domestic and local students should be a two-way dynamic process, and not only expected from international students (Vaughan et al. 2014).

To mitigate cross-cultural misunderstanding, intercultural communication course should be a part of the curriculum for all the students intending or currently 
studying abroad. This could help them move from ethnocentric to ethno-relative worldview and avoid too hasty judgments in regard to CSO representatives and other host nationals. In their turn, CSOs should also provide intercultural training to their volunteers working with international students. Finally, both CSOs and universities should improve their communication and presentation skills to deliver their message to students clearly.

Acknowledgments: The author would like to thank the editor and anonymous reviewers for their valuable comments and helpful suggestions.

\section{References}

Aiden, H. S. 2018. "Understanding Integration Policy-Making in Japan using a Field Analytical Approach: Case Studies of Osaka and Yokohama." PhD diss, UK: University of Bristol. https://research-information.bristol.ac.uk/files/188583227/Final_Copy_2019_01_23_ Aiden_H_PhD.pdf (accessed January 16, 2020).

Aldrich, D. P. 2012. Building Resilience: Social Capital in Post-Disaster Recovery. Chicago: The University of Chicago Press.

Borg, P. 2018. "What is the JET Programme Really for? A Discussion of Official Discourse and Policy." Gifu Kyoritsu Daigaku Ronshu 52 (2): 89-109. http://gku-repository.gku.ac.jp/ bitstream/11207/274/1/ronshu_52\%282\%29_089_borg.pdf (accessed on January 19, 2020).

Coleman, J S. 1988. "Social Capital in the Creation of Human Capital." American Journal of Sociology 94 (Supplement: Organizations and Institutions: Sociological and Economic Approaches to the Analysis of Social Structure): S95-S120. http://www.jstor.org/stable/ 2780243 (accessed October 27, 2018).

Deci, E. L. 1971. "Effects of Externally Mediated Rewards on Intrinsic Motivation." Journal of Personality and Social Psychology 18 (1): 105-15.

Ellison, N. B., C. Steinfield, and C. Lampe. 2007. “The Benefits of Facebook 'Friends': Social Capital and College Students' Use of Online Social Network Sites.” Journal of Computer-Mediated Communication 12: 1143-68.

Encinas, A. P. 2016. "The Role of Student Associations in Providing Community Involvement and Integration between Domestic and International Students." Conference Proceedings of the 27th ISANA International Education Conference, 7-9 December 2016, ISANA International Education Association. http://2016.isanaconference.com/wp-content/uploads/2016/02/ FullPaper_AdrianaPerezEncinas.pdf (accessed May 17, 2019).

Fleischman, D., M. Raciti, and M. M. Lawley. 2010. “A Typology of International Student Community Engagement." e-Journal of Business Education and Scholarship of Teaching 4 (2): 13-26. http://www.ejbest.org/upload/eJBEST_Fleishman_Lawley_Raciti_2010_2.pdf (accessed September 17, 2019).

Fukuyama, F. 2001. “Social Capital, Civil Society and Development.” Third World Quarterly 22 (1): 7-20. https://www.researchgate.net/publication/44828808_Social_capital_civil_society_ and_development (accessed October 27, 2018). 
Haddad, M. A. 2007. Politics and Volunteering in Japan: A Global Perspective. Cambridge: Cambridge University Press.

Harvey, C. 1991. An Examination of the Role and Functioning of International Student Organizations at a State Land Grant University. PhD diss, The Ohio State University.

Hendrickson, B., D. Rosen, and R. K. Aune. 2011. "An Analysis of Friendship Networks, Social Connectedness, Homesickness, and Satisfaction Levels of International Students." International Journal of Intercultural Relations 35 (3): 281-95.

Japan Student Services Organization (JASSO). 2019.International Students in Japan 2018. https:// www.jasso.go.jp/en/about/statistics/intl_student/data2018.html (accessed October 10, 2019).

Japan Student Services Organization (JASSO). 2015. International Students in Japan 2014. https:// www.jasso.go.jp/en/about/statistics/intl_student/data2014.html (accessed October 10, 2019).

Johnson, R. B., and L. Christensen. 2014. Educational Research: Qualitative, Quantitative and Mixed Approaches, 5th ed. Thousand Oaks, California: Sage.

Knight, J. 2004. “Internationalization Remodeled: Definition, Approaches and Rationale.” Journal of Studies in International Education 8 (1). https://journals.sagepub.com/doi/pdf/10.1177/ 1028315303260832 (accessed February 20, 2019).

Krause, K-L. 2005. "Understanding and Promoting Student Engagement in University Learning Communities." Keynote address at James Cook University Symposium, Sharing Scholarship in Learning and Teaching: Engaging Students, 21-2. Queensland: Townsville/Cairns. September 2005.

Maclure, R., and M. Sotelo. 2014. "Youth Social Capital Formation in Nicaragua: A Neighborhood Inquiry." International Journal of Children's Rights 22 (2014): 385-413.

Marginson, S., C. Nyland, E. Sawir, and H. Forbes-Mewett. 2010. International Student Security. Cambridge: Cambridge University Press.

McClelland, D. C. 1987. Human Motivation. New York: University of Cambridge.

Mirwaldt, K. 2012. "The Small Projects Fund and Social Capital Formation in the Polish-German Border Region: An Initial Appraisal.” Regional Studies 46 (2): 259-72.

Muriisa, R. K., and I. Jamil. 2011. "Addressing HIV/AIDS Challenges in Uganda: Does Social Capital Generation by NGOs Matter?” SAHARA-J: Journal of Social Aspects of HIV/AIDS 8 (1): 2-12.

Neri, F. V., and S. Ville. 2008. "Social Capital Renewal and the Academic Performance of International Students in Australia." Journal of Socio-Economics 37 (4): 1515-38.

Otmazgin, N. K. 2018. "The Chrysanthemum and the Cool: Cultural Diplomacy and Soft Power in Japan's Foreign Policy." In Routledge Handbook of Japanese Foreign Policy, edited by M. M. McCarthy, 55-70. Abingdon, UK: Routledge.

Owens, A. R., and S. L. Looms. 2010. "Managing and Resourcing a Program of Social Integration Initiatives for International University Students: What are the Benefits?" Journal of Higher Education Policy and Management 32 (3): 275-90.

Pekkanen, R. 2006. Japan's Dual Civil Society: Members Without Advocates. Stanford: Stanford University Press.

Putnam, R. 1993. Making Democracy Work: Civic Traditions in Modern Italy. Princeton: Princeton University Press.

Putnam, R. 2000. Bowling Alone: The Collapse and Revival of American Community. New York: Simon \& Schuster.

Reimann, K. D. 2010. The Rise of the Japanese NGOs: Activism from Above. Abington: Routledge. 
Schwarz, F. J., and S. J. Pharr. 2003. The State of Civil Society in Japan. Cambridge: Cambridge University Press.

Soubeyran, A., and S. Weber. 2002. "District Formation and Local Social Capital: a (Tacit) Coopetition Approach." Journal of Urban Economics 52 (1): 65-92. https://econpapers.repec. org/article/eeejuecon/v_3a52_3ay_3a2002_3ai_3a1_3ap_3a65-92.htm (accessed October 27, 2018).

Stevens, C. S. 1997. On the Margins of Japanese Society: Volunteers and the Welfare of the Urban Underclass. London: Routledge.

The Ministry of Economy, Trade and Industry (METI). December 25, 2018. "METI and JETRO Embark on New Portal Website 'Open for Professionals': Attracting More Highly-Skilled Foreign Professionals.” https://www.meti.go.jp/english/press/2018/1225_001.html (accessed May 7, 2020).

The Ministry of Economy, Trade and Industry (METI). April 5, 2019. "New Support Measures for Active Participation of Highly-skilled Foreign Professionals in Mid-ranking Enterprises and SMEs." https://www.meti.go.jp/english/press/2019/0405_001.html (accessed May 7, 2020).

Ting-Toomey, S. 2015. “Identity Negotiation Theory.” In Sage Encyclopedia of Intercultural Competence, edited by J. Bennett, Vol. 1, 418-22. Los Angeles, CA: Sage.

Tsujinaka, Y. 2010. “Civil Society and Social Capital in Japan.” In International Encyclopedia of Civil Society, Vol. 1, 252-58. New York: Springer.

Vaughan, S., T. Sanders, N. Crossley, P. O’Neill, and V. Wass. 2014. "Bridging the Gap: The Roles of Social Capital and Ethnicity in Medical Student Achievement." Medical Education 49 (1): 114-23.

Vogt, G., and P. Lersch. 2007. Migrant Support Organizations in Japan: A Mixed-Method Approach. Japan 2007: Politik, Wirtschaft und Gesellschaft, 265-85. Muenchen: ludicium. https://www. dijtokyo.org/doc/JJB_2007_Vogt_Lersch_FINAL.pdf (accessed October 10, 2018). 